Available online at http://jddtonline.info REVIEW ARTICLE

\title{
ANTIOXIDANT ACTIVITY OF VARIOUS PARTS OF PUNICA GRANATUM: A REVIEW
}

\author{
${ }^{1}$ Gunjan Jadon*, ${ }^{2}$ Rahul Nainwani, ${ }^{2}$ Divya Singh, ${ }^{2}$ Praveen K Soni, ${ }^{2}$ Diwaker A K. \\ Pacific College of Pharmacy. Udaipur, India
}

Department of Pharmacology Jaipur College of Pharmacy, Jaipur, India

*Correspondence author's E-mail: nainwani.rahul29@gmail.com

Received 04 Sep 2012; Review Completed 12 Oct 2012; Accepted 01 Nov 2012, Available online 15 Nov 2012

\begin{abstract}
Punica granutam is popularly known as pomegranate (Anar). It is a member of Punicaceae The pomegranate, Punica granatum L., which can be found throughout the Mediterranean region, in Southeast Asia, California and Arizona in USA was in ancient times referred as possessing powers of fertility, abundance and good luck (fruit). The different parts used as raw drugs include root, stem, flower, fruit, twigs exudates and modified plant organs. For centuries, the leaves, flowers, fruits, and seeds of this plant have been used to treat various diseases. Pomegranate is rich in bioactive compounds, mainly polyphenols and anthocyanins, with known health benefits, due to its high antioxidant capacity. The aim of this present review is to throw light on the antioxidant activity of various parts of pomegranate.

Keywords:: Punicaceae, Punica granatum, Pomegranate
\end{abstract}

\section{INTRODUCTION}

Punica granatum L. (Punicaceae), commonly called pomegranate, described as nature's power fruit, is a plant used in folkloric medicine for the treatment of various diseases ${ }^{1}$. Punica granatum L. is a shrub, usually with multiple stems, that commonly grows $1.8-4.6 \mathrm{~m}$ tall. The deciduous leaves are shiny and about $7.6 \mathrm{~cm}$ long. Punica granatum has orange-red, trumpet-shaped flowers with ruffled petals. The flowers are about $5 \mathrm{~cm}$ long, often double, and are produced over a long period in summer. The fruit is globose, 5-7.6 $\mathrm{cm}$ in diameter, and shiny reddish or yellowish green when mature. The fruit is technically a berry. It is filled with crunchy seeds, each of which is encased in a juicy, somewhat acidic pulp that is itself enclosed in a membranous skin. Punica granatum grows well in warm areas and is cultivated throughout Jordan, where it is popularly known as "roman"2. Pomegranate is a native fruit from Iran to the Himalayas in Northern India and it has been both cultivated and naturalized throughout the whole Mediterranean region since ancient times ${ }^{3}$. Oxidative stress is responsible for many of today's diseases that result from an imbalance between formation and neutralization of pro oxidants. Oxidative stress is initiated by free radicals, which seek stability through electron pairing with biological macromolecules such as proteins, lipids and DNA in healthy human cells and cause protein and DNA damage along with lipid per oxidation ${ }^{4}$.

\section{ANTIOXIDANT POTENTIAL OF VARIOUS PART OF POMEGRANATE}

\section{Seeds}

$>\quad$ Gill et $\boldsymbol{a l}$ (2012) have reported the antioxidant activity of the wild Punica granatum ethanolic seed extract and measured by 1,1-diphenyl-2-picrylhydrazyl and hydrogen peroxide free radical scavenging method. Further it was evaluated for its anti-ulcer activity by pyloric ligation model in wistar albino rats. Gastric volume, ulcerative index and free and total acidity were measured in this model. The extract and $74.91 \pm 0.235$ at $100 \mu \mathrm{g} \mathrm{mL-'}$ by 1,1-diphenyl-2picrylhydrazyl and hydrogen peroxide method respectively as compared to the (ascorbic acid) in case of quantitative analysis and showed yellow coloration with 1,1-Biphenyl-2- picrylhydrazyl scavenging radical in case of qualitative analysis. In pyloric ligation method, the extract showed optimum percentage inhibition of $74.51 \%$ at $100 \mu \mathrm{g} \mathrm{mL-}$ which was comparable to the standard (ranitidine). It concluded that wild $P$. granatum ethanolic seed extract possesses significant antioxidant and anti-ulcer activities ${ }^{5}$.

Pedriali et al (2010) have studied that the Pomegranate seeds extract lost $79 \%$ of its antioxidant activity during light exposure. The extract was divided into two samples: protected from light, (Extract 1), or not, (Extract 2). The extracts were characterized by UV-Visible absorption spectroscopy, quantification of total phenolics by the FolinCiocalteu method, and the antioxidant activity was determined by the DPPH quenching method. Extract 2 presented $9.8 \%$ less total polyphenols than Extract 1 . The pomegranate seeds extract lost $79 \%$ of its antioxidant activity during light exposure Extract 1 up to $3 \%(\mathrm{w} / \mathrm{v})$ showed neither cyto nor phototoxicity in the Hela cells. ${ }^{3}$

Sadeghi et al (2009) have studied that extracts obtained from Pomegranate seeds using various solvents exhibited various degrees of antioxidant activity. The ferric reducing/antioxidant power assay (FRAP) was employed and the FRAP value of the seed fraction of six different cultivars of Pomegranate in Iran was determined in an attempt to compare their differing antioxidant acitivity. The antioxidant activity of seed fraction of six different cultivars of Pomegranate in water extracts showed that the Sour white peel cultivar has the highest FRAP value $(3.45 \pm 0.85 \mu \mathrm{M})$ and the Agha Mohamad Ali cultivar has the lowest value $(2.76 \pm 0.76 \mu \mathrm{M})$; ethanolic extract of the seeds showed that Sour white peel and Black peel cultivars have the highest $(3.88 \pm 1.31 \mu \mathrm{M})$ and lowest $(1.62 \pm 0.47 \mu \mathrm{M})$ antioxidant activity. Results indicated that the extracts obtained from pomegranate seeds using various solvents exhibited various degrees of antioxidant activity. ${ }^{6}$

Rind

$>\quad$ Rajan et al (2011) have evaluated the phytochemical and in vitro antioxidant properties of Punica granatum fruit rind extract. DPPH assay, reducing power assay, nitric oxide radicals scavenging, superoxide radical 
scavenging, ABTS scavenging, hydrogen peroxide scavenging assay were the method adopted to study antioxidant potentials of extracts. Standard methods were used to screen preliminary phytochemistry and quantitative analysis of tannin, phenolics \& flavanoids. Aqueous and alcoholic extracts were showed good antioxidant effect with IC50 ranges from $34.78 \pm 14.04$ to $135.27 \pm 35.5 \mu \mathrm{g} / \mathrm{ml}$ for aqueous and $40.03 \pm 14.72$ to $105.93 \pm 17.19 \mu \mathrm{g} / \mathrm{ml}$ for alcoholic extracts. Phenolic compounds, tannins and flavonoids were the major phytochemicals present in both the extracts. Percentage of inhibition increased with the increased concentration of extracts. The aqueous and alcoholic extract yielded $122.33 \pm 6.42 \& 176 \pm 5.29 \mathrm{mg} / \mathrm{g}$ gallic acid equivalent phenolic content $135.33 \pm 8.08 \& 81.33 \pm 6.1 \mathrm{mg} / \mathrm{g}$ quercetin equivalent flavonoid and $81.66 \pm 3.51 \& 114.23 \pm 12.16 \mathrm{mg} / \mathrm{g}$ tannic acid equivalent tannins respectively. The present study provides evidence that both extracts of $P$. granatum fruit rind is a potential source of natural antioxidant.

Devatkal et al (2010) have studied that the overall anti-oxidant effect was in the order of Pomgranate rind powder (PRP)> Pomgranate rind powder (PSP)> Kinnow rind powder (KRP). Total phenolic content, DPPH radical scavenging activity and effect of these extract on instrumental color sensory attributes and TBARS values during storage of goat meat were evaluated.It was concluded that extracts of above fruits by-product powders have potential to be used as natural anti-oxidants in meat product. $^{7}$

\section{Peel}

$>\quad$ Dikmen et al (2011) have studied the pharmacological activities, (such as antioxidant and anticancer) of Punica granatum peel. They evaluated the relation with its antiproliferative and apoptotic effects on MCF-7 human breast cancer cells. Total phenolic content and antioxidant activity of PPE were determined using the FolinCiocalteau and the 2,2-diphenyl-1-picrylhydrazyl free radical methods, respectively. Phenolic acids present in the extract were characterized by a reverse-phase high-performance liquid chromatography (HPLC) method. Cell proliferation was assessed by the 3-(4, 5-dimethylthiazol-2-yl)-2,5diphenyltetrazolium bromide reduction assay. PPE has important antioxidant and apoptotic effects. After 48 and 72 hours, the apoptotic cell numbers were significantly increased at 100, 200, and $300 \mu \mathrm{g} / \mathrm{mL}$ PPE concentrations. In addition, expression of the pro-apoptotic gene Bax was increased, and that of the anti-apoptotic gene Bcl-2 was decreased after 200 and $300 \mu \mathrm{g} / \mathrm{mL}$ PPE treatment for 48 and 72 hours. Because PPE reduced cell proliferation and induced apoptosis on MCF-7 cancer cells, we believe that PPE has important antioxidant and apoptotic effects. ${ }^{8}$

$>\quad$ Moneim (2011) has studied the efect of Pomgranate juice and peel on liver and kidney of male rats. Eighteen adult male albino rats were randomly divided into three groups, six rats of each. The first group served as control and received saline $(0.2 \mathrm{ml}$ saline/rat) by oral administration via epigastric tube. The second group received oral administration of $3 \mathrm{ml} / \mathrm{kg}$ pomegranate juice for 21 days and served as pomegranate juice (PJ) group. The third group received oral administration of $200 \mathrm{mg} / \mathrm{kg}$ methanol extract of pomegranate peel for 21 days and served as methanol extract of pomegranate peel (MEPP) group. Pomegranate has no effect on liver and kidney functions. PJ and MEPP reduced lipid peroxidation and nitric oxide in both liver and kidney tissue homogenate. A significant increase in superoxide dismutase and catalase activities of rats received pomegranate was observed. This finding have demostrated that pomegranate has potent antioxident effect. ${ }^{1}$ peel had higher yield and content than those from the seeds. The yield and content of antioxidants increased with reduced particle size and increased water/sample ratio and temperature, but antioxidant activity was low when extraction temperature was high. The recommended extraction conditions were peel particle size of $0.2 \mathrm{~mm}$, water/peel ratio of 50/1 (w/w), temperature of $25 \mathrm{C}$, and extraction time of $2 \mathrm{~min}$, which gave the high antioxidant yield $(11.5 \%)$ and content $(22.9 \%)$, and DPPH scavenging activity of $6.2 \mathrm{~g} / \mathrm{g} .{ }^{9}$

Osama et al (2010) have studied the antioxidant effect of Punica granatum peel methanolic extract (10 and $20 \mathrm{mg} / \mathrm{kg}$ ) against oxidative damage in streptozotocin-induced diabetic rats. The antioxidant activity of $P$. granatum peel extract was investigated by examining the level of antioxidant enzymes, catalase (CAT), superoxide dismutase (SOD), glutathione peroxidase (GPx), glutathione-Stransferase (GST) and glutathione reductase (GR), the serum total antioxidant capacity and lipid peroxidation in the tissues of treated diabetic rates comparing with normal and untreated diabetic ones. The results revealed that intraperitoneal administration of 10 and $20 \mathrm{mg} \mathrm{kg}^{-1}$ (body weight) of $P$. granatum peel extract for 4 weeks significantly enhanced the activities of antioxidant enzymes in liver, kidney and RBC of STZ-induced diabetic rats. The extract also caused a significant reduction in malondialdehyde (MDA), a lipid peroxide's marker, in diabetic rat tissues and elevated the total serum antioxidant capacity in dose-dependent manner.The peel extract shows potent antioxident effect. ${ }^{10}$

Zahin et al (2010) have studied the broad spectrum antioxidant and antimutagenic activities of peel extracts of pomegranate. The sequentially extracted Punica granatum peel fractions were tested for their antioxidant activity by DPPH free radical scavenging, phosphomolybdenum, FRAP $(\mathrm{Fe}(3+)$ reducing power) and CUPRAC (cupric ions $(\mathrm{Cu}(2+))$ reducing ability) assays. The methanol fraction showed highest antioxidant activity by all the four in vitro assays comparable to ascorbic acid and butylated hydroxy toluene (BHT) followed by activity in ethanol, acetone, and ethyl acetate fractions. Based on the promising antioxidant activities, the methanol fraction was evaluated for antimutagenic activity by Ames Salmonella/microsome assay against sodium azide $(\mathrm{NaN}(3))$, methyl methane sulphonate (MMS), 2-aminofluorene (2-AF) and benzo(a)pyrene (B(a)P) induced mutagenicity in Salmonella typhimurium (TA97a, TA98, TA100 and TA102) tester strains. The methanol fraction showed no sign of mutagenicity at tested concentration of $10-80 \mu \mathrm{g} / \mathrm{mL}$. This fraction showed antimutagenic activity against $\mathrm{NaN}$ (3) and MMS with percent inhibition of mutagenicity ranging from $66.76 \%$ to $91.86 \%$ in a concentration-dependent manner. Similar trend of inhibition of mutagenicity $(81.2-88.58 \%)$ against indirect mutagens (2-AF and $\mathrm{B}(\mathrm{a}) \mathrm{P})$ was also recorded. ${ }^{11}$

Salgado et al (2004) have studied that the highest antioxidant activity in Pomegranate peels than in seeds and pulp. The results showed that the pomegranate peel was used to produce dried extract that was added Pomegranate peel was used to produce dried extract that was added to commercial tomato juice and orange juice with strawberries. Analysis to determined the content of phenolic compounds and antioxidant activity was performed on Pomegranate pulp, seedsand peel. The dried extract was responsible for significant increase in antioxidant activity of the juices, proportional to the concentrationsadded. ${ }^{12}$ 
$>\quad$ Moneim (2004) has screend the methanol extract of Punica granatum peel or its antioxidant activity on brain of adult male Wistar albino rats. The antioxidant activity was determined by measuring reduced glutathione, catalase, superoxide dismutase, glutathione reductase, glutathione-Stransferase, and glutathione peroxidase Pomegranate peel treatment resulted in marked increase in most antioxidant parameters with reduction in oxidant $\mathrm{H}_{2} \mathrm{O}_{2}$, NO and MDA. Results concluded that pomegranate methanol peel extract is a promising natural product, which could be useful for the prevention of neurodegenerative diseases caused by oxidative stress. ${ }^{13}$

\section{Fruit}

$>\quad$ Cambay et al (2011) have studied that oxidative stress induced by diabetes mellitus leads to damages in the brain, as a consequence of which cognitive functions is impaired. Pomegranate fruit supplementation was decreased oxidative stress and ameliorates impairment in learning and memory performances in diabetic rats. ${ }^{14}$

Kishore et al (2009) have studied the role of Pomegranate (Punica granatum L.) fruit extract which has shown antioxidant capacity higher than that of red wine and green tea against adriamycin-induced oxidative stress in chick embryos. however, its prolonged use is limited by an irreversible, dose-dependant and progressive cardiomyopathy, hepatotoxicity and general toxicity to other organs in human beings, due to oxidative stress. The morphological changes (malformation of different organs), changes in body weight, volume of amniotic fluid (AF) and biochemical parameters of AF were studied after 24 and $48 \mathrm{~h}$ of incubation by comparing ADR alone and pomegranate fruit extract pretreated groups with their respective controls of 12 days old chick embryos. ADR alone at a dose of $70 \mu \mathrm{g} / \mathrm{egg}$ showed a significant dose versus time- dependent reduction in body weight, volume of AF. A dose-related increase in embryo gross morphological deformities and significant changes in the levels of biochemical parameters in AF were observed in ADR-treated group. These changes were significantly ameliorated to normal by preadministration of pomegranate fruit extract at a dose of 200 $\mu \mathrm{g} / \mathrm{egg}$. The study demonstrated the embryo protective nature of pomegranate fruit extract against ADRinduced oxidative stress. ${ }^{15}$

\section{Juice}

$>\quad$ Ricci et al (2006) have studied that the arils, juice and rinds of Punica granatum fruits and their aqueous and ethyl acetate extracts displayed good antioxidant activity. The activity was evaluated by DPPH test, 5 lipooxygenase assay and luminol/xantine/ xantine oxidase system Pomgranate arils, juice and rinds exhibted always higher antioxident activity than their aqueous and ethyl acetate extracts. $^{16}$

Balbir et al (2004) have studied that Pomegranate extract (POMx 10ml /day for 12 weeks) consumption has been shown to reduce the incidence and severity of collageninduced arthritis in mice. POMx to serum from RA patients reduced free radical-induced lipid peroxidation by up to $25 \% .^{17}$

$>\quad$ Gil et al (2000) have evaluated the antioxidant activity of Pomegranate juices was by four different methods (ABTS, DPPH, DMPD, and FRAP) and compared them to red wine and a greentea infusion. Commercial pomegranate juices showed an antioxidant activity (18-20 TEAC) three times higher than those of red wine and green tea (6-8 TEAC). HPLC-DAD and HPLC-MS analyses of the juices revealed that commercial juices contained the pomegranate tannin punicalagin $(1500-1900 \mathrm{mg} / \mathrm{L})$ while only traces of this compound were detected in the experimental juice obtained from arils in the laboratory. It showed that pomegranate industrial processing extracts some of the hydrolyzable tannins present in the fruit rind. This could account for the higher antioxidant activity of commercial juices compared to the experimental ones ${ }^{18}$

\section{Flowers}

- Kaur et al (2006) have reported that alcoholic (ethanolic) extract of Pomgranate flowers showed $81.6 \%$ antioxidant activity in DPPH model system. The ability of extract to scavenge reactive oxygen species (ROS) and reactive nitrogen species (RNS) was tested and it was found to significantly scavenge superoxide $\left(\mathrm{O}_{2}^{--}\right)$(by up to $53.3 \%$ ), hydrogen peroxide $\left(\mathrm{H}_{2} \mathrm{O}_{2}\right)$ (by up to $30 \%$ ), hydroxyl radicals $(\mathrm{OH})$ (by up to $37 \%$ ) and nitric oxide (NO) (by up to $74.5 \%$ ). I.P injection of $9 \mathrm{mg} / \mathrm{kg}$ Fe-NTA to mice induced oxidative stress in liver injury. Pertreatment with 50-150 $\mathrm{mg} / \mathrm{kg}$ extract for week significantly and dose dependently protected against Fe-NTA induced oxidative stress. The extract afford $60 \%$ protection lipid peroxidation and preserved glutathione levels and activities of antioxidant eanzymes viz., catalase glutathione peroxidase, glutathione reductse and glutathione-S-transferase by up to36\%,28.5\% and $28.7,40.2 \%$ and $42.5 \%$.

19

\section{CONCLUSION}

The pomegranate has been an inexhaustible source of research going from chemistry in the search for new compounds, techniques of production and conservation, biotechnology in search of more profitable varieties. ${ }^{20}$ After extensive literature reports on the medicinal properties of pomegranate it is easy to understand why researchers have referred to the pomegranate as "nature's power fruit" 21. Pomegranate is a potent antioxidant, superior to red wine and equal to or better than green tea. The antioxidant activity of various parts of pomegranate is measured by the different methods. Based on the literature precedence, most of the important research about Pomegranate and its antioxidant activity has been performed during the past decade.

\section{REFRENCES}

1. Moneim A., Dkhil M., Quraishy., "Studies on the effect of Pomegranate (Punica granatum) juice and peel on liver and kidney in adult male rats" Journal of Medicinal Plants and Research,2011,5(20),5083-88

2. Qnais E.Y., Elokda A.S., Ghalyun Y.Y., Addulla F.A.,“Antidiarrheal activity of the aqueous extract of Punica granatum (Pomegranate) Peels", Pharm Biol,2007,45(9);715-20

3. Pedriali A, Fernandes AU, Santos P, Silva M M, Severino D, Dilva M B., "Antioxidant activity, cito- and phototoxicity of Pomegranate (Punica granatum L.) seed pulp extract", Cienc. Tecnol. Aliment,2010, 30(4);1017-21

4. Rajan S.,Mahalakshmi S, Deepa V.M.,Sathya K.,Shajitha S.,Thirunalasundarii T "Antioxidant potentials of Punica granatum fruit rind extracts" ,International Journal of Pharmacy and Pharmaceutical Sciences, 2011,3(3);82-88. 
5. Gill N.S., Dhawan S., Jain A., Arora R., Bali M., "Antioxidant and anti-ulcerogenic activity of wild Punica granatum ethanolic seed extract", Research Journal of Medicinal plants, 2012,6(1);47-55.

6. Sadegi N., Jannat B Oveisi M. R., Photovat M., “Antioxidant activity of iranian Pomegranate (Punica granatum L.) seed extracts", J. Agri. Sci. Tech., 2009,11; 633-38

7. Devatkal SK, Narsaiah K, Borah A., "Anti-oxidant effect of extracts of kinnow rind, Pomegranate rind and seed powders in cooked goat meat patties" Meat Sci, 2010,85(1):155-9

8. Dikmen M, Ozturk N, Ozturk Y. "The antioxidant potency of Punica granatum $\mathrm{L}$. Fruit peel reduces cell proliferation and induces apoptosis on breast cancer" J. Med. Food. 2011, 14(12):1638-46.

9. $\mathrm{Qu} \mathrm{W}$, Zhongli P, Haile M., "Extraction modeling and activities of antioxidants from Pomegranate marc", Journal of Food Engineering ,2010,99,16-23

10. Osama Y. A.,Ahmed H., Tarawneh K.Khaled M. Khleifat M K.,B.H Ridzwan B , Qaralleh N "Protective role of Punica granatum L. peel extract against oxidative damage in experimental diabetic rats" Process Biochemistry,2010,45(4);581-85

11. Zahin M, Aqil F, Ahmad I., "Broad spectrum antimutagenic activity of antioxidant active fraction of Punica granatum L. peel extracts", Mutat Res. 2010,703(2):99-107

12. Salgado M. J, Ferreira B R., Biazotto., Dias S., "Increased antioxidant content in juice enriched with dried extract of Pomegranate (Punica granatum) peel" Plant Food Hum Nutr,2012,67;39-43

13. Moneim E A., "Antioxidant activities of Punica granatum (pomegranate) peel extract on brain of rats" Journal of Medicinal plants Resreach,2004,6(2);195-99

14. Cambay Z, Baydas G, Tuzcu M, Bal R. "Pomegranate (Punica granatum L.) flower improves learning and memory performances impaired by diabetes mellitus in rats" Acta Physiol Hung. 2011,98(4):409-20.

15. Kishore R K., Sudhakar D., Parthasarathy P.R., "Embryo protective effect of Pomegranate (Punica granatum L.) fruit extract in adriamycin-induced oxidative stress", Indian Journal of Biochemistry \& Biophysics, 2009,43;106-11

16. Ricci D.,Giamperi L,Bucchini A, Fraternale D "Antioxidant activity of Punica granatum fruits", Fitoterapia,2006,77(4); 310-12

17. Balbir-Gurman A, Fuhrman B, Braun-Moscovici Y, Markovits D, Aviram M. "Consumption of Pomegranate decreases serum oxidative stress and reduces disease activity in patients with active rheumatoid arthritis: a pilot study", Isr Med Assoc J. 2011,13(8); 474 9 .

18. Gil M I., Francisco A., Hess-Pierce B, Deirdre M.Adel A. K." "Antioxidant activity of Pomegranate juice and its relationship with phenolic composition and processing", J. Agric. Food Chem. 2000, 48; $4581 \mathrm{~s}-4589$

19. Kaur G, Jabbar Z, Athar M ,Alam S, "Punica granatum (pomegranate) flower extract possesses potent antioxidant activity and abrogates Fe-NTA induced hepatotoxicity in mice" Food and Chemical Toxicology, 2006,44;982-93

20. Miguel M.G,Neves M. A., Maria D. Antunes2 "Pomegranate (Punica granatum $\mathrm{L}$.): A medicinal plant with myriad biological properties - A short review" .,Journal of Medicinal Plants Research,2010, 4(25);2836-2847

21. Prakash C.V.S ,Prakash I., "Bioactive Chemical Constituents from Pomegranate (Punica granatum) Juice, Seed and Peel-A Review" International Journal of Research in Chemistry and Environment, 2011, 1 (1); 1-18.

Table 1: Reported research work on antioxidant activity of various parts of punica granatum

\begin{tabular}{|c|c|c|c|}
\hline Plant part & Type of extract & Model used & Author \\
\hline Seed & Ethanolic extract & $\begin{array}{l}\text { 1,1-diphenyl-2-picrylhydrazyl and hydrogen peroxide } \\
\text { free radical scavenging method }\end{array}$ & Gill et al (2012) \\
\hline Rind & Aqueous and alcoholic extracts & $\begin{array}{l}\text { DPPH assay, reducing power assay, nitric oxide } \\
\text { radicals scavenging, superoxide radical scavenging, } \\
\text { ABTS scavenging, hydrogen peroxide scavenging } \\
\text { assay }\end{array}$ & Rajan et al (2011) \\
\hline Peel & Methanolic Extract & $\begin{array}{l}\text { Folin-Ciocalteau and the } \\
\text { picrylhydrazyl free radical methods }\end{array}$ & Dikmen et al (2011) \\
\hline Seeds & Hydroalcoholic extract & DPPH quenching method & Pedriali et al (2010) \\
\hline Peel & Methanolic extract & lipid peroxidation and nitric oxide & Moneim (2011) \\
\hline Juice & Juice & lipid peroxidation and nitric oxide & Moneim (2011) \\
\hline $\begin{array}{l}\text { Seeds and } \\
\text { peel marc }\end{array}$ & Aqueous & DPPH scavenging activity & Qu et al (2010) \\
\hline Peel & Methanolic extract & $\begin{array}{l}\text { the level of antioxidant enzymes and lipid } \\
\text { peroxidation }\end{array}$ & Osama et al (2010) \\
\hline Peel & $\begin{array}{l}\text { Methanolic, ethanolic, ethyleacetate } \\
\text { and Butaylated Hydroxy toulene } \\
\text { extract }\end{array}$ & $\begin{array}{l}\text { DPPH free radical scavenging, phosphomolybdenum, } \\
\text { FRAP }(\mathrm{Fe}(3+) \text { reducing power) and CUPRAC } \\
\text { (cupric ions }(\mathrm{Cu}(2+)) \text { reducing ability) assays }\end{array}$ & Zahin et al (2010) \\
\hline Peel & Methanolic extract & $\begin{array}{l}\text { glutathione, catalase, superoxide dismutase, } \\
\text { glutathione reductase, glutathione-S-transferase, and } \\
\text { glutathione peroxidase }\end{array}$ & Moneim (2004) \\
\hline $\begin{array}{l}\text { Arils, juice } \\
\text { and rinds }\end{array}$ & $\begin{array}{l}\text { Juice and aqueous and ethyl acetate } \\
\text { extracts }\end{array}$ & $\begin{array}{lcccc}\text { DPPH test, } 5 & \text { lipooxygenase } & \text { assay } & \text { and } \\
\text { luminol/xantine/ xantine oxidase system }\end{array}$ & Ricci et al (2006) \\
\hline Fruit & Juice & free radical-induced lipid peroxidation & Balbir et al (2004) \\
\hline Juice & Juice & ABTS, DPPH, DMPD, and FRAP & Gil et al (2000) \\
\hline Flowers & Ethanolic extract & $\begin{array}{l}\text { reactive oxygen species (ROS) and reactive nitrogen } \\
\text { species }\end{array}$ & Kaur et al (2006) \\
\hline
\end{tabular}

